\title{
Gênero e vida doméstica de mulheres em relacionamento estável na pandemia covid-19
}

\section{Gender and domestic life of women in stable relationships in the covid pandemic}

\section{Paula Fabricia Brandão Aguiar Mesquita', Maria do Socorro Ferreira Osterne²}

1. Professora do Curso e do Mestrado em Serviço Social da Universidade Estadual do Ceará (UECE). Doutora em Sociologia (UfC) com Pós- doutorado em Serviço Social (uEce). Vice coordenadora do Laboratório de Direitos Humanos, Cidadania e Ética. https://orcid.org/0000-0002-3477-1255 paula.brandao@uece.br

2. Professora dos Programas de Pós-Graduação em Sociologia, em Políticas Públicas e do Mestrado em Serviço Social da Universidade Estadual do Ceará-Uece. Livre Docência em Serviço Social pela uece, doutora em Serviço Social (ufpe) e Coordenadora adjunta do Núcleo de Acolhimento Humanizado às Mulher em situação de Violência-NAH-UEcE. https://orcid.org/0000-0001-5627-6784 socorro.osterne@uece.br

Resumo: Visa a compreender os papéis femininos e a vida doméstica de mulheres em tempos de pandemia, ocasionada pela covid-19. Durante meses, milhões de mulheres, em todo o mundo, em situação de quarentena, viveram intensamente o âmbito da domesticidade, trabalho remoto e cuidados familiares. Busca-se entender como as mulheres vivenciaram esse cotidiano, uma vez que as tarefas de casa sempre foram a elas delegadas, ainda que os intensivos movimentos feministas tensionassem as dinâmicas desse ambiente. A investigação foi feita mediante envio de questionário do Google Forms, com 
mulheres cearenses, de segmentos médios urbanos, e revelou que, embora tenha havido maior acerto na divisão do trabalho doméstico, ainda permanece uma relação indolente e que precisa continuar em avanço nas próximas décadas, ratificada pelo discurso de esgotamento e sofrimento das entrevistadas, nesse período.

Palavras-chave: Gênero. Vida Doméstica. Pandemia covid-19.

Abstract: This investigation aims to understand female roles and the domestic life of women in times of pandemic of the covid-19. In the last months, millions of women from all over the world in quarantine experienced intense stress in the context of domestic life, home office and family care. If one seeks to understand how women live this daily life, they have always been delegated the housework while intensive feminist movements intended To understand and modify the dynamics of this environment. The investigation was carried out by sending a questionnaire of Google Forms to women from Ceará, Brazil, from medium urban segments, and the research revealed that, even if they were successful in the domestic work division, there was still an indolent relationship. The feminist movement which must continue to advance in the coming decades, ratified by the speech of exhaustion and suffrage of women interviewed during this period of confinement.

Keyword: Feminism; genre. Domestic life. Coronavirus; Pandemic Covid19

\section{Introdução}

O mundo inteiro foi - e continua sendo - objeto de um grave abalo em 2020. Fomos surpreendidos por uma das maiores pandemias virais da história da humanidade, que devasta populações de todos os continentes e famílias inteiras. Ao começar em um país tão distante, a China, não tínhamos a dimensão espaciotemporal de que essa doença covid-19 nos tiraria, tão rapidamente, de nossos ocupados cotidianos e remeteria a condições jamais vivenciadas. $\mathrm{O}$ mundo lá fora parou, a máquina enguiçou, mas os trabalhos para dentro das casas assumiu outro status - o de obrigação contínua e interminável.

Para alguém que esteja lendo de algum lugar do futuro, o sentimento 
que vivemos, nesse momento, é de perplexidade ante uma narrativa ficcional moderna, que nos dizia que o homem (e a mulher, naturalmente) era potência, capaz de dominar a natureza ilimitadamente. Acabamos de descobrir que não; não somos! Esse vírus invisível mostrou-nos, cruelmente, que a humanidade é frágil, nos atingindo no que mais prezávamos: a nossa liberdade. A ideia deste texto não é trazer dados epidemiológicos sobre a covid-19, tampouco o crescente número de mortos e contaminados, numa sequência de mais de mil óbitos a cada 24 horas, dia após dia. Interessa, portanto, falar de dentro das nossas casas, presas em apartamentos, como vivenciamos, na condição de mulheres, essa epidemia. A nós é ensejado relatar sobre a aflição de mães ao verem os filhos cerceados do direito a brincar com os amiguinhos e estudar; acerca de compartilhar uma rotina doméstica de lavar pratos e roupas, varrer, fazer comida; a respeito da novidade do trabalho remoto diário e das reuniões por videoconferência; enfim, no que concerne a acompanhar os filhos em seus estudos indiretos, uma vez que, eles - tampouco suas professoras - não tinham a menor ideia de como fazê-lo, pois, conforme é consabido, tudo foi inusitado.

Durante todo o decurso da tentativa de compreendermos essa doença e suas influências negativas em nossos quotidianos, tornou-se perceptível a ideia de que a população mais vulnerável e demandante de políticas públicas compensatórias esteja sendo a mais dizimada. São, sobretudo, as mulheres pobres, negras, a população LGBTQI, moradores de rua, dentre outros. Evidenciamos, contudo, que o motor deste escrito foi assente em observações feitas nas redes sociais, principalmente por grupos de Whats $A p p$, tornado meio por excelência de comunicação, porquanto era defeso que nos tocássemos. Foi por via do acompanhamento de grupos de condomínio compostos por famílias; de grupamentos de mães de escolas infantis, além de contingentes familiares, que evidenciamos um discurso constante: as mulheres manifestavam exaustão no cumprimento do papel, do qual elas procuram se desvincular, de modo contundente, pelo menos nos últimos quatro séculos, ou seja, do cuidado dos filhos, do lar e do locus privado da casa. Esses relatos que chegaram também por intermédio de ligações de amigas, colegas de trabalho e outras pessoas conhecidas, nos fizeram despertar para montar um questionário a ser aplicado através 
da plataforma Google, sobre a vida sexual e doméstica de mulheres casadas ou em relacionamento estável, que estavam passando a pandemia com seus companheiros(as). Enviamos para grupos de estudos das universidades, para alguns condomínios, conjuntos familiares, agrupamentos de escolas, e conhecidos das mais diversas ordens. Para nossa surpresa, em menos de 24 horas, já haviam sido preenchidos mais de 100 questionários, perfazendo, em sete dias, o quantitativo de 370 retornos.

Foi um grande alvoroço de mulheres ligando, mandando print de suas respostas marcadas e áudios: “olha aí o que eu marquei!", além de dezenas de mensagens pessoais. $\mathrm{O}$ conteúdo do questionário era composto por um perfil socioeconômico das mulheres e por perguntas sobre como vivenciavam a vida doméstica e conjugal, antes e durante a pandemia. E foi sobre esses indicadores que nos debruçamos, tentando compreendê-los, à luz das teorias de gênero, para comentar como as mulheres respondentes que vivem a grande peste do século XXI, situando esse debate em seu plano histórico e social.

\section{Mulheres em quarentena: considerações sobre gênero e vida doméstica em tempos de pandemia}

As mulheres têm servido há séculos como espelhos, com poderes mágicos e deliciosos de refletir a figura do homem com o dobro do tamanho natural. Sem esse poder, provavelmente a terra ainda seria pântanos e selvas. As glórias de todas as nossas guerras seriam desconhecidas(...) Super-homens e Dedos do Destino nunca teriam existido. (woolf, 2014: p. 54) - Um teto todo seu.)

Esse período revela-se profícuo em reflexões a respeito de como as pessoas viveram até agora a pandemia e quais suas estratégias de sobrevivência. Schwartz (2020), em seu breve ensaio sobre esse momento histórico, alude à ideia de que o século xx só acaba com o fim da pandemia, de igual maneira como Hobsbawn dizia que o século XIX só terminaria em 1918, após conclusa a Primeira Guerra Mundial. O século xx foi a era da tecnologia e da crença de que seu advento nos libertaria. Veio, todavia, um ser minúsculo, o vírus da 
covid-19, provando que somos vulneráveis demais, e que um século não se vira apenas mudando uma folhinha do calendário. Aliás, sobre esta matéria, convém atentarmos para a necessidade do aprofundamento de nossas análises atinentes a todos os indicativos que se incorporaram à convulsão trazida pelo coronavírus, quais sejam, as crises do processo civilizatório ocidental moderno e de hegemonia dos Estados Unidos, bem como a própria crise estrutural do capitalismo em sua versão ultraneoliberal.

Com efeito, a pandemia nos empurrou, bruscamente, para dentro de nossas casas, e tivemos - como expressa Schwartcz (2020) - que reinventar a nossa rotina e nos descobrir como uma pessoa estrangeira. Isso vale para homens e mulheres, de todas as idades, classes e etnias. $\mathrm{Na}$ avaliação da autora, entretanto,

[n]ós, mulheres, por exemplo, temos um conhecimento distinto dos homens quanto ao cuidado da casa. Não há nada de biológico nessa constatação; essa é uma função que nos foi impingida histórica e culturalmente de modo a aparecer "natural”, o que não é. (2020, n.p).

Essa naturalização é constatada, por exemplo, no relato de uma mulher, em um grupo de WhatsApp, ao revelar que, durante a pandemia, o marido tentou ajudá-la, mas o "coitado" (sic) não tinha jeito para fazer nada, ficava tudo mais bagunçado, de sorte que ela preferiu assumir todo o trabalho. Ela é uma profissional liberal, que tem quatro filhos e, afora ter certo reconhecimento entre seus pares, disse que a pandemia a fez repensar que talvez seus filhos precisassem mais dela, doravante. Connell e Pearse (2015) assinalam:

Não podemos pensar o ser mulher ou o ser homem como experiências fixadas pela natureza. Mas também não podemos pensá-los apenas como uma imposição externa realizada por meio de normas sociais ou da pressão de autoridades. As pessoas constroem a si mesmas como masculinas e femininas. Reivindicamos um lugar na ordem do gênero - ou respondemos ao lugar que nos é dado -, na maneira como nos conduzimos na vida cotidiana. (p.39). 
$\mathrm{Na}$ contramão desse discurso, entretanto, a maioria das mulheres revela que ficar em casa significou uma sobrecarga exaustiva de trabalhos domésticos, ainda que, no período de pandemia, houvesse "muitos braços em casa", para dividir o trabalho reprodutivo. A casa é, também, uma ambiência de conflitos. As mulheres veementemente, exprimem nesses canais de informação a noção de que, no período da pandemia, estão se sentindo exaustas. Ficar em casa, obrigatoriamente, não trouxe sossego para elas, pois, ao contrário, provocou uma enorme dificuldade prática na condução do dia a dia, exacerbando a responsabilidade de grande parte do trabalho doméstico, o qual, histórica e preponderantemente, já lhes compete.

O experimento sob relato consistiu na busca de uma aproximação com mulheres em período de isolamento social, manifesta pela plataforma on line Google Forms. O período de recolhimento dos 370 questionários foi de 02 a 09 de junho de 2020, com base geográfica em Fortaleza - Ceará, a capital que, circunstancialmente, relatava o maior número de contaminados por covid-19 no País. As apreensões reveladas aqui foram também compostas por informações coletadas em grupos de Whats $A p p$ e redes sociais, como já referido. Esses meios se consolidaram como locis de encontro, serviram para aproximar milhares de pessoas e mobilizar amplas discussões sobre suas vivências. Em tempo algum os media digitais foram tão usados, para manifestações das subjetividades e de emoções, como nesses últimos meses.

As mulheres que responderam aos 370 questionários tinham idade de 30 a 45 anos (77,8\%), sendo os intervalos etários mais presentes, o de 30-35 anos $=21,9 \%$. Todas são casadas ou em situação de relacionamento estável. Definiram-se, majoritariamente, como heterossexuais $93,8 \%, 3,5 \%$ bissexuais; 2,7\% homossexuais. Ou seja, são mulheres adultas, em relacionamentos heterossexuais, numa sociedade cis-hetero-patriarcal.

Em termos de escolaridade, a maioria possui diploma de pós-graduação $(65,5 \%)$ e $21,5 \%$ graduação. Representam, com efeito, um grupo de mulheres privilegiadas nos segmentos urbanos médios, pois conseguiram chegar aos bancos universitários, em um país da América do Sul, sabidamente desigual e com profundas dificuldades de acesso às circunstâncias institucionais. Nessa 
perspectiva, Birole e Miguel (2014) ratificam o fato de que, em 2009, quase $60 \%$ dos estudantes matriculados no ensino superior do Brasil eram do sexo feminino, entre mulheres brancas, que representavam $23,8 \%$, enquanto as negras situavam-se com percentual menor do que $10 \%$.

Por outro lado, o fato de terem acesso a estudos superiores não tem correspondência direta com posições equânimes no mercado de trabalho, comparativamente aos homens, consoante asseguram Birole e Miguel (2014):

O rendimento mensal médio dos trabalhadores homens é, por sua vez, quase o dobro das mulheres (...) há quase três vezes mais mulheres do que homens entre quem ganha até meio salário mínimo, mas há crescentemente menos mulheres nas faixas de renda a partir de dois salários mínimos, e essa proporção se inverte quando se chega ao topo da pirâmide. (p. 10).

Das pesquisadas, no entanto, observamos que 84,9\% (314) exercem função retribuída financeiramente e suas remunerações variam de 3 a 5 salários-mínimos (30,2\%); entrementes, 28,8\% percebem de 6 a 10 salários-mínimos. Notemos que estes dados indicam, sobretudo, que estas interlocutoras conseguiram subir alguns degraus a mais do que a maioria das mulheres. São, portanto, pessoas privilegiadas, que tiveram direito a ficar em casa na quarentena, protegendo a sua saúde e a de seus filhos. Convém destacar, ainda, o fato de que $9,9 \%$ delas recebem mais de 16 salários-mínimos.

Lahire (2002), em seus estudos sobre classe média, revela que os indivíduos são depositários de disposições de pensamento, sentimento e ação produzidas em suas experiências socializadoras múltiplas, ou seja, sua pertença acontece nos mais diversos grupos de interação. Assim, ao analisar as múltiplas faces dessas mulheres das camadas médias urbanas de Fortaleza, percebemos aspectos diferenciados de escolaridade, rendas mensais, bem como de revelações de sua rotina doméstica. Nada mais social, para Lahire, do que os problemas pessoais, aqueles não indiferentes a nenhuma pessoa, afinal, o mundo social está dentro e fora de nós. É em determinado lugar social que apreendem disposições e hábitos determinados. O próprio modo como cada qual reage às tensões, a 
exemplo de como lidam com a situação de uma pandemia, o fato de estarem isoladas em casa depende de suas vivências, como responderam, em outros contextos, a determinadas situações, à extensão de suas vidas.

Essas mulheres, que reafirmam determinadas condições de enfrentamento a esse período de pandemia, pelo fato de representarem segmentos das classes sociais médias, têm o próprio modo de responder e criar perspectivas de enfrentamento às adversidades impostas pela situação atual. Já possuíam uma reserva de capital cultural e social, que lhes possibilitou uma vivência menos sofrida desse momento, quando muitos morrem por dificuldades de acesso a saúde, que transpõem qualquer ponto essencialmente de classe, mas que, concomitantemente, é imprescindível revelar, por outro lado, o modo pelo qual determinadas camadas, que vivem nas franjas sociais, desprovidas de direitos, adoecem e morrem nesse processo, por não terem, sequer, como deixar de trabalhar nos chamados serviços essenciais.

A investigação, portanto, revela aspectos da vida de mulheres com o perfil de segmentos médios, com ensino superior, que trabalham fora de casa, casadas e com filhos. Del Priore (2000) assegura que, quando a mulher intenta conciliar os papéis familiares e profissionais, ela é obrigada a criar estratégias complexas para dar conta da "dobradinha infernal." Em sua avaliação, a carga mental e a sucessão de atividades profissionais, domésticas e de cuidados dos filhos as sobrecarregam. Essa ocorrência reflete os 12,7\% (47) das mulheres que responderam, que faziam tudo sozinhas. Uma delas revelou, nas respostas abertas: "(me sinto) sobrecarregada, porque além da casa, tem a escola dos meus filhos e quero trabalhar." É nesse momento que ela restringe seu bem-estar ou oportunidade de lazer.

Quando quer investir-se profissionalmente, ela acaba por hipotecar sua vida familiar ou usar todo tipo de astuciosa bricolagem, sacrificando o tempo livre que teria para seu prazer e seu lazer e que poderia estar sendo vivido na esfera doméstica. Muitas mulheres, menos afortunadas, são assim empurradas para uma pesadíssima jornada de trabalho. (DEL PRIORE, p.13). 
Uma das motivações para buscar um diagnóstico de como estavam, de fato, vivendo as mulheres na pandemia, veio pelo vasto número de relatos que nos chegavam sobre mulheres que colheram os frutos da revolução sexual e da mudança dos paradigmas que as circunscreveram no âmbito da domesticidade. Giddens (1993) é assertivo, ao dizer que, mesmo com a independência, algumas ainda estruturam sua vida em termos do casamento. Ainda assim, no entanto, traçam alterações na autoidentidade, à medida que se confrontam com as mudanças nos modelos de casamento, na dinâmica familiar e no trabalho, persistindo a ideia de que ter um relacionamento é também ser uma mulher bem-sucedida. Goldenberg (2010), por sua vez, aponta que, no Brasil, há uma riqueza por demais valiosa entre as mulheres, que é ter marido, constituindo um verdadeiro capital, nomeado capital marital, pois as casadas se acham valorizadas e superiores às demais.

$\mathrm{Na}$ quarentena, motivada pela pandemia da covid-19, na qual as pessoas necessitam de isolamento social em suas residências, apareceu, intensivamente, esse conflito, como uma espécie de retorno à domesticidade, que parecia resolvida, mas que, de fato, havia sido varrida para debaixo do tapete, portanto, foi enfrentada de maneira retumbante. Schwartz (2020) constata que nem sempre casa é lar. Casa é um abrigo, lugar de repouso, ao passo que lar é um conceito burguês, que idealiza esse local como o modelo de família estruturada, no século xix. Ou seja, à margem de qualquer ideação sobre o lar, é preciso mostrá-lo como algo contraditório, que reúne projetos e perspectivas diferentes de quem lá reside. Conforma, também, uma noção essencialmente relacionada à ideia de família, instituição identificada por Osterne (2001), como

[...] algum lugar, seja o lar, a casa, o domicílio, o ponto focal, onde se possa desfrutar do sentido de pertencer, onde se possa experimentar a sensação de segurança afetiva e emocional, onde se possa ser alguém para o outro, apesar das condições adversas e mesmo independente das relações de parentesco e consanguinidade. Algo que possa ser pensado como o local de retorno, o destino mais certo. Local para refazer-se das humilhações sofridas no mundo externo, expandir a agressividade reprimida, exercitar o autocontrole, repreender, vencer o outro, enfim, sentir-se parte integrante. (p. 92). 
Configura, pois, uma definição situada na contramão daquele conceito dominante de família, principalmente nas classes mais abastadas, portanto, também nos estratos médios, qual seja, aquele agrupado que congrega um conjunto de palavras afins: pai, mãe, filhos e filhas, casa, unidade doméstica, casamento e parentesco.

Com efeito, a família considerada "legítima", "normal", que se abriga no imaginário da maioria das pessoas, caracteriza-se como um conjunto de pessoas aparentadas que se unem por aliança, casamento, filiação, adoção ocasional ou afinidade. É pressuposto comum a noção de que essas habitem sob um mesmo teto, materializado na noção de casa. Essa imagem corresponde, historicamente, ao modelo da família nuclear burguesa. Qualquer outro paradigma fora desse padrão será remetido à ideia de família desestruturada. No âmbito desta realidade, o trabalho doméstico aparece como um marcador robusto de gênero, porquanto, culturalmente, atribuído às mulheres.

O trabalho doméstico - diz Perrot (2017) - é fundamental nas sociedades e na vida das mulheres. Elas são sempre educadas para serem donas de casa e, malgrado as revoluções feministas e sociais, esse problema nunca foi solucionado, uma vez que poucos homens dividem tais atividades. O pano, a pá, a vassoura, o esfregão e o rodo continuam a ser instrumentos femininos por excelência. Trata-se de um trabalho que parece continuar o mesmo, desde a origem dos tempos, da noite das cavernas à alvorada dos conjuntos habitacionais." (p.115). A autora observa que são três as figuras desse locus doméstico: a dona de casa de origem humilde, a dona de casa burguesa e a criada, que, atualmente, assume o papel de empregada doméstica ou diarista.

As mulheres dos estratos médio e alto, ainda hoje, assumem a lógica de serem servidas, não mais por criadas, mas por empregadas domésticas ou diaristas. Estas mantêm uma complexa relação com suas patroas, envolvendo relação de trabalho e vinculações pessoais na condição de oprimidas, em situações diferenciadas na sociedade cis-hetero-patriarcal.

Rubin (1978) avisa que a resposta que damos quando tratamos da opressão das mulheres nos diz muito se é realista ou não esperar por uma sociedade sem hierarquias de gênero e socialmente igualitária. Assim, conforme avalia, se 
o sexismo é subproduto do capitalismo, o socialismo, então, deveria ser capaz de exterminá-lo.

Fala-se, em especial por meio de Slavoj Zizec (2020), que as bases do capitalismo ficaram fragilizadas com a pandemia que abrange todo o mundo. E que atravessamos os seguintes estágios:

Primeiro, houve a fase da negação, em que se insistiu em dizer: "Não há nada grave ocorrendo, há apenas alguns indivíduos irresponsáveis disseminando pânico". Depois, o sentimento de raiva - muitas vezes sob forma racista ou anti-Estado: "Os culpados são os chineses sujos ou a ineficiência do Estado em lidar com esse tipo de crise”. Na sequência, entram os raciocínios da fase de negociação: "Ok, há algumas vítimas, mas a situação é menos grave que a sARs e ainda podemos limitar o estrago;" E se nada disso funcionar, bate a depressão ("Não nos enganemos mais, estamos todos perdidos"). Mas como seria a aceitação aqui? É estranho constatar que essa epidemia apresenta um traço em comum com a última rodada de protestos sociais ocorridos na França, em Hong Kong, na América Latina etc., a saber: não são fenômenos que explodem e depois passam; eles permanecem e simplesmente perduram, trazendo medo e fragilidade permanentes a nossas vidas. (2020, n.p).

Em decorrência da necessidade de afastamento social, lockdown, muitas lojas e empresas passaram muitos meses fechadas, e uma parte significativa delas já pediu falência, além do que milhões de desempregados(as) engrossaram as filas na busca por trabalhos. Perguntamos, então: se as bases do capitalismo estão de fato submetidas a xeque, será que a pandemia possibilitará repensar a naturalização e os lugares delegados historicamente às mulheres? Convém, antecipadamente, pensar que essas mudanças contingenciais não progridam no período pós-pandemia, uma vez que uma transformação cultural leva muito tempo para ser absorvida em qualquer modelo de sociabilidade.

É facilmente notório que, durante esta pandemia, o papel que as mulheres ocupam na reprodução social e sexual não tenha se modificado de maneira impactante. Pelo menos, em termos. Elas talvez tenham vivenciado, durante 
esse período, as mais sutis e profundas modalidades de opressão. Saíram, de inopino, dos seus sítios de trabalho fora de casa, signo de conquistas históricas dos movimentos feministas, para, bruscamente, serem reposicionadas num lugar de onde lutaram muito para sair: o lar! Esse talvez expresse o mais avassalador incômodo vivido por essas mulheres, qual seja, a volta para os lugares onde suas mães e avós foram obrigadas a viver. Ao serem questionadas sobre como se sentiam na pandemia, podendo opções múltiplas, revelaram os seguintes sentimentos: 45,4\% (168) diziam estar ansiosas; 36,2\% (134) angustiadas; $34,6 \%$ (128) exaustas; $17,8 \%$ (66) nervosas; $16,2 \%$ (60) tristes.

Em seus argumentos, observamos as dificuldades sentidas, quando diziam que não aguentavam mais ficar dentro de suas casas. Em diário de campo, registramos o fato de que, tanto aquelas que tinham posições destacadas no mercado de trabalho, como as trabalhadoras informais, diziam não querer ficar mais em casa. No concernente a esse aspecto, Rubin (2011) pergunta, parafraseando Marx:

O que é uma mulher do lar? Uma fêmea da espécie. Uma explicação é tão boa contra a outra. Ela só se transforma numa criada, numa esposa, numa escrava, numa coelhinha do playboy, numa prostituta, num dita fone humano em determinadas relações. Apartada dessas relações, ela já não é a companheira do homem mais do que o ouro é dinheiro etc. O que são essas relações pelas quais uma mulher se transforma numa mulher oprimida?" (RUBIN, 2011, n.p.).

Que relações sociais são gravadas, na carne das mulheres, para que se sintam oprimidas, exaustas e desgastadas ao ficarem no âmbito doméstico? O que é uma esposa? Permanecendo em casa, as mulheres se sentem oprimidas porque a maioria dos homens continua recebendo uma educação que naturaliza os afazeres do lar, como atividades femininas. No Nordeste, por exemplo, eles continuam sendo educados para serem machos e afirmarem sua virilidade por pressupostos diametralmente opostos aos da feminilidade. Existe uma valência diferencial dos sexos, que conforme Héritier (2002) reflete características 
diferentes ao masculino e feminino, e sugere uma submissão da mulher ao homem, situando cada um de um lado do pólo: "quente/frio, seco/úmido, activo/passivo, rugoso/liso, forte/fraco [...] aventureiro/caseiro.” (HÉRITIER, 2002, p.16). Num inquérito de opinião pública foi perguntado quais os maiores acontecimentos do século xx. E assim foi respondido: os homens disseram que foi a ida à lua, e noventa por cento das mulheres responderam que foi o direito à contracepção. Isso significa, de acordo com a autora:

A grande revolução da nossa época não é a conquista espacial. É antes a conquista das mulheres do Ocidente de um estatuto de pessoas autônomas juridicamente reconhecido que lhes era negado até então. Na minha opinião, o eixo desta conquista é o direito de dispor de si própria que lhes dá a contracepção através da retomada do controle da fecundidade nas suas mãos. Graças a contracepção, a mulher torna-se dona do seu corpo e já não é considerada um simples recurso; utiliza seu livre arbítrio em matéria de fecundidade, inclusive na escolha do cônjuge, na escolha do número de filhos que deseja e o momento em que deseja tê-los. (p.102).

O momento da "viragem" foi essa separação entre desejo e reprodução. Contudo, ao refletir sobre a dimensão do cuidado, da responsabilidade pelos afazeres da casa, muito ainda há para avançar. A autora ainda revela:

A repartição das tarefas no mundo doméstico é, pois, o resultado de uma história milenar e de uma invariância estrutural cujos conteúdos escapam necessariamente aos atores de hoje, num momento em que continuam a vivê-la. É tanto mais sólida porquanto é interiorizada pelos dois sexos em função de grelhas de valor onde se situam os atos da vida quotidiana segundo o sexo socialmente esperado do ator e as condições do meio: cozinhar ou tirar algo do poço não são atos masculinos em praticamente todo o mundo. Mas fazê-lo de forma assalariada é uma atividade masculina que não implica nenhum opróbio.” (p.258-259). 
A estrela Michelin, honraria maior do setor da indústria internacional para os chefs de cozinha, no último ano, concedeu nove, das dez medalhas para homens. Ou seja, os papéis naturalizados para mulheres são aqueles que não remuneram, ou não permitem independência total. Na pandemia, quando interpeladas sobre o significado da vida doméstica durante a pandemia, as mulheres revelaram: $41,6 \%$ (154) se sentem sobrecarregadas, pois, além das atividades domésticas, continuam com trabalho remoto. Já 28,4\% amenizam e dizem se sentirem bem desenvolvendo atividades domésticas; 5,4\% (20) revelaram que o trabalho remoto é motivo de angústia; 4,1\% (15) disseram ser motivo de desespero. Nas perguntas abertas, uma delas explica os motivos da exaustão: "Me sinto sobrecarregada, pois temos o mesmo trabalho, mas com relação à casa faço quase tudo sozinha, enquanto o trabalho remunerado é igual para os dois."

As novas tecnologias da informação ora respondem pela continuidade dos trabalhos não presenciais. Essas atividades remotas, somadas às tarefas domésticas, e às obrigações escolares dos filhos, apareceram como fonte de grande estresse, pois, para as mulheres, significou acúmulo de responsabilidade, como refere as respostas dadas abaixo: "Me sinto cansada com as atividades remotas dos meus filhos e meu trabalho, porque tudo tem prazo e a adaptação é complicada"; "Sobrecarregada, porque além da casa, tem a escola dos meus filhos e quero trabalhar"; ou ainda: "Frustração, por não conseguir manter a limpeza em padrões melhores de qualidade.” (ANOTAÇões DE PESQUisA).

Essa geração que hoje tem de 30 a 39 anos, não vivenciou o modelo da dona de casa profissional, ou seja, da "rainha do lar", antes, porém, a ideia de polivalência. Na tensão entre o antigo modo de ser da mulher na sua domesticidade e a busca por independência, Pinsky (2012) revela o outro modelo, o da mulher-maravilha, advindo dos anos de 2000, que "[...] corre feito louca para dar conta da profissão, da família e das tarefas domésticas - ainda deve encontrar tempo para ir à academia de ginástica e o [sic] salão de beleza.”(p. 533). A associação da imagem da mulher à condição de trabalhadora, guerreira, sem descuidar dos afetos e deveres de mãe, ainda é valorizada. E quem não consegue fazer tudo, se frustra, atrai sobrecarga, tentando manter metas de alcance impossível. 
Há um aspecto transversal, sobretudo, ao pensarmos que $88,4 \%$ das pesquisadas relataram que ficaram em casa em quarentena. As profissões das mulheres situam-se na zona soft, em trabalhos nas áreas sociais, consideradas mais leves, de menor remuneração e atuantes no cuidare. Parte dessas profissionais liberais, que foram pesquisadas, ficou em casa na quarentena. São professoras, psicólogas, advogadas, comerciantes - profissionais liberais dos mais diversificados ofícios. Impõe-se ressaltar que aí também laboram enfermeiras, assistentes sociais e médicas que estavam na linha de frente no enfrentamento ao covid-19, em hospitais e serviços públicos de saúde, adoecendo e morrendo.

A pesquisa interpelou sobre quem fazia suas atividades domésticas antes da pandemia, e as respostas foram as seguintes: $34,3 \%$ (127) empregada doméstica, $9 \%$ (83) pela diarista, ou seja, 56,7\% das entrevistadas tinham o trabalho doméstico feito por uma pessoa terceirizada. Esse modelo revela um perfil de classe, um estilo de vida que delega determinadas atividades domésticas consideradas pesadas para trabalhadoras domésticas moradoras das periferias dos centros urbanos. Ávila (2013) adverte para a noção de que essas relações foram tecidas pelos fios da dominação/exploração patriarcal e racista, incontornavelmente vinculados ao decurso de formação brasileira. Consoante examina a autora, em 2013, havia 6,6 milhões de trabalhadores domésticos no País, dos quais $92,6 \%$ eram mulheres, sendo, destas, $61 \%$ negras, revelando a imbricação das relações sociais de sexo, raça e classe.

Releva evidenciar o fato de que um grupo de mulheres, 30, 5\%, afirma dividir as atividades com o companheiro, representando 113 das entrevistadas, em um universo de 370. Esse dado é significativo pelo fato de revelar algum acerto histórico, na divisão sexual do trabalho, entre pessoas das camadas médias. Ainda que a divisão sexual do trabalho nunca tenha sido resolvida por completo, com a revolução sexual, esse aspecto já mostra algum avanço, relativamente à histórica situação de indolência que caracterizava essas relações de gênero, preteritamente - sobretudo se considerarmos que a resposta seguinte era "o companheiro ajuda nas tarefas domésticas". Quem ajuda faz quando pode, não havendo um combinado do que cada um se responsabiliza. 
Difere, portanto, de repartir o que seria um passo importante rumo à equidade de gênero no âmbito das atividades reprodutivas características do espaço privado da casa, dos homens e das mulheres.

Quando, porém, indagadas se algo mudou no decorrer da pandemia, houve significativa alteração para $41,6 \%$, ao responderem que o companheiro dividia as atividades domésticas com as mulheres. Em seguida, 36,8\% registram que o companheiro ajuda em algumas atividades. Finalmente, 21,6\% (78) revelaram que têm filhos, por cujas atividades remotas respondem, na condição de mães.

A ideia de passar por uma pandemia, o sofrimento ocasionado pela supressão da dita normalidade, a falta de liberdade para sair de casa, não encontrar as pessoas, não poder trabalhar fora, o medo de adoecer ou mesmo morrer - que permeou o cotidiano de todos que ficaram em isolamento social - configuraram a realidade propícia para profundas reflexões e adoção de outros hábitos e comportamentos. $\mathrm{O}$ contato mais próximo com filhos e maridos, numa dinâmica que não permitia, necessariamente, liberdade de espaço, mas orientação de afastamento, ensejou grandes tensões. Por outro lado, deu ensejo a vivências de compartilhamento, mesmo que fossem para fazer a limpeza e cozinhar, dentre outras ações peculiares à vida caseira. Daí, para concluir que essas mudanças de comportamentos se fortaleçam e perpetuem no pós-pandemia, será preciso ainda esperar alguns ciclos e mais observar, uma vez que o tempo é muito exigente quando se trata de está em propósito a efetivação de mudanças culturais. Contudo, não há, todavia, como negar evidências e modificações ocorridas nos modelos mais conservadores de relacionamento familiar.

\section{Considerações finais}

Ouvimos bastante, ultimamente, as pessoas de nosso relacionamento e os media expressarem que a sobrevivência ao coronavírus precisa também ser uma questão feminista. Antes, porém, independentemente da condição de gênero, convém dizer que experienciamos muitas ansiedades e incertezas, guardando a impressão de que não estávamos, minimamente, preparadas para vivenciar essa pandemia.

Os panoramas ainda são ambíguos, paradoxais e contraditórios, haja vista a maneira despreparada como nosso País se posicionou para enfrentar esta 
batalha sanitária, submetendo a risco muitas vidas. É perceptível, também, o argumento de que os períodos de crise costumam agravar as incertezas e aumentar os questionamentos.

No tocante às mulheres, temos um chefe de governo que rejeita os feminismos, ao tachá-los de ideologia, e negligencia a luta pelos direitos delas. Uma coisa, entretanto, parece certa: se nossa senda política foi estabelecida pelos homens e por estes dominada, sob a égide do modelo cis-hetero-patriarcal, racista e preconceituoso, essa pandemia, contraditoriamente, indica possibilidades de libertação por meio das mulheres, haja vista a profunda necessidade da recomposição dos afetos em torno da razão, dos cuidados pessoais e coletivos, das vivências grupais, enfim, por ter tornado evidente a necessidade de uma sociedade do cuidado e da valorização do trabalho doméstico reprodutivo.

Embora os homens estejam dividindo mais as tarefas domésticas e os cuidados com os filhos, continua cabendo muito mais às mulheres, mais uma vez, um clássico problema enfrentado pelas feministas, qual seja, elas prosseguem arcando com o acúmulo e a sobrecarga das tarefas no ambiente familiar. Como consequência do dito sobrepeso, o cansaço físico e emocional é passível de enfraquecer seu sistema imunológico, deixando as mulheres mais sujeitas às infecções e outras patologias correlatas.

Outro aspecto importante a ser ressaltado diz respeito à onda crescente de violência física e sexual contra as mulheres, subnotificadas durante este período, versus o distanciamento das redes de proteção. Outro destaque concerne ao caso das mulheres que estão na linha de frente do combate à Covid-19, uma vez que o mercado de trabalho na área de saúde ainda é fortemente marcado por matérias de gênero. No cálculo revelado por Pisani (2020), em escala global, as mulheres representam cerca de $70 \%$ da força de trabalho na seara da saúde. Elas, também, é que ocupam grande parte dos trabalhos informais e de meio expediente. Nesse período, muitas desistiram de seus empregos para permanecerem em casa cuidando dos filhos e de suas famílias. Estas, certamente, terão dificuldades para retornar ao mercado após a pandemia.

Esta pesquisa desvela, mais especificamente, o perfil de mulheres de classe média. Se as ideações acima expressas lhes causam sérios problemas, estes serão 
bem mais graves no caso das pobres e negras que exercem trabalhos informais. Aliás, esta pandemia, em contextos de sociedades individualistas, machistas, racistas, acentuou, sobremaneira, as modalidades de dominação capitalista e patriarcal.

No que é pertinente a esta dimensão, comenta o autor lusitano Boaventura de Sousa Santos (2020):

As pandemias não matam tão indiscriminadamente quanto se julga. São menos discriminatórias que outras violências cometidas contra os trabalhadores empobrecidos, mulheres, trabalhadores precários, negros, indígenas, imigrante, refugiados, sem abrigos, camponeses e idosos. (p.23).

À maneira de remate, exprimimos a ideia de que, não obstante cruel, a pandemia não se perfaz como a responsável direta pelo imenso mal-estar que se instala em nossa sociedade globalizada/capitalista. Isso já sucedia por meio de uma brutal expansão das desigualdades, por via da inaceitável persistência da miséria e da fome e em razão da indiferença ante a morte de milhares de excluídos sociais nas periferias dos sistemas. Também, entretanto, pelas tentativas de matarem os sistemas democráticos e pela flagrante negligência nos modi operandi relativamente aos problemas climáticos (Buratim,2020).

Nesta caminhada, aprendemos algumas lições. Assim, doravante, será imprescindível: combater as desigualdades e a diferença de privilégios; enfrentar as falsas informações; fortalecer a ciência; proteger o meio ambiente e continuar cuidando da higiene e da saúde de todos.

No futuro próximo, portanto, nos restam dois caminhos: ou mudamos nossa razão de mundo, alicerçada na ética do bem comum, ou alimentaremos a involução civilizatória. E, nessa empreitada, será de muita importância a participação das mulheres. Por conseguinte, para um desfecho mais promissor, tornar-se-á imperiosa a necessidade da reconstituição das bases éticas de convivência entre homens e mulheres, e de orientação de nossas instituições. 


\section{Referências}

ÁVILA, Maria Betânia. O tempo do trabalho doméstico remunerado: entre cidadania e servidão. In HIRATA, Helena: ABREU, Alice Rangel de Paiva. (orgs.). Gênero e Trabalho no Brasil e na França: perspectivas interseccionais. São Paulo: Boitempo, 2016.

BIROLI, Flávia. Feminismo e Política. São Paulo: Boitempo, 2014.

BURATIM, Ricardo. A crise do coronavírus e o neoliberalismo: o que está em questão? Carta Capital. Opinião. 04 de abril,2020.

DEL PRIORE, Mary. História das Mulheres no Brasil. São Paulo: Editora Unesp, 2008.

DEL PRIORE, Mary. Corpo a corpo com a mulher. Pequena história das transformações do corpo feminino no Brasil. São Paulo: Senac, 2000.

GIDDENS, Anthony. A transformação da Intimidade. Sexualidade, Amor e Erotismo nas Sociedades Modernas. São Paulo: Editora Unesp, 1993.

GOLDENBERG, Mirian. Intimidade. Rio de Janeiro: Record, 2010.

GOLDMAN, Wendy. Mulher, Estado e Revolução: política familiar e vida social soviética, 1917-1936. São Paulo: Boitempo, 2014.

HEILBORN, Maria Luiza. Dois é par. Gênero e Identidade sexual em contexto igualitário. Rio de Janeiro: Garamond Universitária, 2004.

HÉRITIER, Françoise. Masculino e feminino/II. Dissolver a hierarquia. Lisboa, Portugal: Instituto Piaget, 2002

OSTERNE, Maria do Socorro Ferreira. Família, Pobreza e Gênero: o lugar da dominação masculina. Fortaleza: EDUECE, 2001.

PERROT, Michelle. Minha história das Mulheres. São Paulo: Contexto, 2017.

PINSKY, Carla. A era dos modelos flexíveis. In PINSKY, Carla (org.). Nova História das mulheres. São Paulo: Contexto, 2012.

PISANI, Mariane. O enfrentamento e a sobrevivência ao coronavírus também precisa ser uma questão feminista. Boletim n.12 - Ciências Sociais e coronavírus. 2020. 
SANTOS, Boaventura de Sousa. A Cruel Pedagogia do Vírus. Coimbra: Edições Almedina. Abril, 2020.

SCHWARCTZ, Lilia M. Quando acaba o século XX. São Paulo: Companhia das Letras, 2020.

RUBIN, Gayle. 0 tráfico de mulheres: notas sobre a economia política do sexo. In Políticas de Sexo. São Paulo: Ubu, 2011.

WOOLF, Virgínia. Um teto todo seu. São Paulo: Tordesilhas, 2014.

ZIZEC, Slavoj. Pandemia. Covid-19 e a reinvenção do comunismo. São Paulo: Boitempo, 2020.

Recebido: 16/05/2021

Aceito:19/11/2021 